\title{
Integration of Art and Design in Mechanical Engineering
}

\author{
M.Y. Ackerman, C. Stout, Mechanical Engineering, University of Alberta; \\ C. Gajewski, Industrial Design, Faculty of Arts, University of Alberta
}

\begin{abstract}
Is Design a process or an art form? Traditionally design has been taught in Engineering as a process that started with the definition of a need for a product or a process and culminated in a deliverable that took the form of a project record and usually a set of manufacturing drawings. There was always a good deal of emphasis on design for manufacturing as well as the minimization of product cost. As a result of this, and our inability to judge "creativity", designs had a tendency to be fully functional but not very esthetically pleasing. In other words the designs worked but, as often as not, were ugly. It seems that most engineers are very "left brained". As a result they are very comfortable with the notion of calculating anything required to make the design functional and cost effective but are not at all comfortable in making the design "work" from an industrial design perspective.

Leading manufacturers of products are not satisfied with designs that are only functional. They recognize that for a product to be successful it must function but must also appeal to the customer. To enable this to happen requires more than the traditional hard calculation of optimal functional parameters; it requires a team approach that brings both the hard technical side and the more artistic industrial design side.
\end{abstract}

\section{Introduction}

The Mechanical Engineering program at the University of Alberta has a design stream that starts in second year and proceeds through third and fourth year. The approach to design is the same in each year but because of the increasing student capabilities at each stage of the undergraduate program the emphasis on various parts of the design process are weighted accordingly.
The design stream attempts to present a unified approach throughout the undergraduate program, laying out a very specific process that follows that shown below.

1) Specification development

2) Project planning

3) Conceptual design

4) Detail design

5) Technical communication of design results

Second year students are just starting to develop the technical background to produce truly viable designs so the emphasis is placed on specification development and project planning. Students are introduced to the notion that they need to outline and define a design space with tangible and specific descriptors as a starting point and become comfortable with the notion that as the design progresses there will very likely be changes or additions to the design specification. The open ended nature of design problems provides an opportunity for design staff to encourage students to think beyond "warm and fuzzy" specifications such as "lowest cost", "light as possible" and to put a hard target in place knowing full well that it may have to be adjusted. This emphasis on specifications and planning does not mean that the students stop at that point, only that we recognize that their skill sets are not fully developed and as such the viability of the designs is often tempered with inexperience.

Third year students bring to the design course, or are concurrently developing, a much more elaborate range of skills. For students at this level the process is the same but the expectation for analysis during both the conceptual design phase and the detail design phase is increased. At this point in the program the students will have additional knowledge and experience in strength of materials, fluid mechanics and heat transfer so their designs are not limited to very basic objects. 
Fourth year students doing the Capstone Design course are expected to be technically competent in all areas from analysis to drawings and modeling as well as presentation. For these students the projects are drawn from industry and the development of specifications is done in concert with a client that has a design problem they are interested in having solved. Design projects range from "industrial widgets" to manufacturing process improvements to medical devices. The course instructors "filter" the projects somewhat to ensure an appropriate level for the skill sets available and that the projects are really design and not simply performance testing of an existing project. That does not mean to say that we do not accept projects that require evaluation with the goal of making performance or cost improvements, only that we do not want the students simply testing an existing product to define performance. Many years ago we recognized that the student designs were heavily driven by cost considerations and that the students did not really appreciate the breadth of potential manufacturing process or economies of scale. As a result, students tended to gravitate to components that were readily available or "off the shelf". This led to generic designs that were fully functional but in a word "ugly".

An opportunity presented itself last fall with a chance meeting with academic members of the Industrial Design community at the University of Alberta. The Industrial Design Unit in the Department of Art and Design at the $U$ of Alberta is a part of the Faculty of Arts. Discussions between Industrial Design and Mechanical Engineering ensued and it was decided that a pilot project involving both departments would be attempted. The Unit of Industrial Design (ID) is small relative to Mechanical Engineering with the ID having 22 senior students. The basic idea was to add one ID student to each mechanical engineering design group and see what happened.

Before delving into the potential benefits and pitfalls of this allegiance it should be emphasized that this collaboration between ID and MecE was perceived by the students as overwhelmingly positive. This was reflected in the weekly one hour meetings between the design instructors and student design groups, the course evaluations completed by the students and the post course debrief held between the course coordinator and selected design groups. The industrial sponsors as well as the judges for the final presentations (most of which had judged previous years design presentations) also noted distinct differences between the designs produced during the trial relative to previous years.
What Worked:

- Students learned of colleague's varied and disparate skill sets

- Students developed a common design language

- Students learned to organize and balance very different schedules

- Visual presentation of both conceptual ideas and final designs was vastly improved

- Clients were very pleased with designs

Areas for Improvement:

- Projects have very different ID potential (wheel chair vs a part that was designed to be incorporated into the internals of a burner)

- Mismatched project, course and learning expectations

- Language barriers; engineering definition of "works" vs industrial design definition of "works"

- Scheduling issues (lecture slots and meeting times)

- Design teams struggled with appropriate and equitable division of labour

- Challenges with CAD interoperability (design software incompatibilities)

- Develop and fine tune a methodology for evaluating very different design projects

Prior to this collaboration senior mechanical engineering students were not familiar with the training, experience and skill sets possessed by their industrial design colleagues, the same was likely true for ID students. Many students had preconceived notions of the skill sets and the first challenge for each was to define for the others what they were capable of contributing to the project. We usually allow senior design teams to choose their own members and subsequently "bid" for projects. Design projects, gathered from industry, student vehicle teams, and other departments on campus, are advertized on a course web page with a one or two page description. Students are given a short amount of time to form groups, examine the projects and contact project sponsors for additional information. The number of groups working on a particular project is restricted to one or two to ensure that most of the design projects are selected as well as to encourage continued participation by our project sponsors. As an interesting side note, groups were interviewed shortly after project selection to evaluate student's 
rationale for project selection. Reasons given for selections were in the order of importance:

- Perceived workload (the project seemed easy)

- Interest in the product and/or design problem

- Project was perceived to be outside mainstream engineering design, i.e. medical devices

- Opportunity to work on something that was unlikely to be encountered in their expected field of work

During the trial period the project selection process was complicated by allowing ID students to independently choose projects and then attempt to match interests with engineering students.. Not surprisingly, industrial design students gravitated towards projects perceived as having significant ID (visual) components and as a result some projects received multiple requests while others had none. Communication and selection of design projects and teams was facilitated through the use of an online forum accessible to both ID and MecE students through eClass (WebCT). Since the project selection phase occurs in the first 10 calendar days of the course there was a rapid reshuffling of ID students to projects and as a result some of the ID students did not get their first project choices. This may have caused some stress early in the projects but by the third or fourth week none of it was evident and the groups had combined to form design teams.

The first challenge faced by both ID and MecE students was to develop and use a common design lexicon. While team discussions were typically conducted in English each discipline had a unique and sometimes confusing vocabulary. For example, the phrase "it works" in the Mechanical Engineering vernacular means the device is functional or performs as intended. In the ID community this phrase means that the product or graphical design appeals to the senses; either visual or haptic. While differences in design language did not cause serious communication problems it required student groups to ensure that they were really discussing the same thing and reach a common understanding. As a result of active listening and deliberate communication, MecE students gained an understanding of industrial design and the ID students came to appreciate the underlying engineering analysis that ensures design functionality, fitness for purpose and longevity.

An unanticipated challenge centered around lecture schedules and meeting times for students from different faculties, each having fundamentally different timetables. Whereas design lectures in the mechanical engineering course were scheduled according to an historic pattern and ID students were most welcome to attend, more often than not schedule conflicts prevented their full participation.

As a result, ID students were forced to rely on second hand information from engineering colleagues regarding project deliverables. Although Mechanical Engineering design lectures were posted on the course web page, this imposed an additional workload on ID students who felt that they should receive the information first hand and not be made responsible for finding it. This situation will be remedied in subsequent collaborative efforts by scheduling selected lectures to fit the ID student's schedules. Mechanical Engineering design groups are typically able to set scheduled work times or meeting times easily because they share similar class and lab schedules. Unfortunately some design teams had a great deal of difficulty incorporating disparate ID student timetables into team work sessions or meeting times simply because the schedules were completely out of phase. While this did not present an insurmountable barrier it meant that in some cases the ID student really acted as a consultant rather than a full fledged member of the design team - in physical presence only.

\section{Course Deliverables}

The senior design course has a very specific set of deliverables associated with it as shown below. Deliverables are tied to design phases with the aim to have the students appreciate that for a project to continue to move forward it must be justified at each stage in terms of cost and suitable progress (and of course a reasonable expectation of a positive outcome). The deliverables tied to each phase are indicated below.

- $\quad$ Project $\&$ Team Selection - review project descriptions, contact project sponsors, form design teams, submit letter of intent [duration 1.5 weeks]

- Phase I, Specification Development \& Project Planning - short written report formalizing the problem definition, preliminary product specifications, design space and project schedule [duration 3 weeks]

- Phase II, Conceptual Designs - short written report comparing three alternative design concepts - complete with appropriate virtual models, concept drawings and supporting calculations [duration 4.5 weeks] 
- Mid Phase Conceptual Design Peer Review - short oral presentation, conceptual design poster and participation in group critique [duration 1 day]

- Phase III, Detail design - concise technical data package describing final design, compliance to specifications, detailed engineering analysis, virtual models and working drawings [duration 4 weeks]

- Design Poster - one page graphic, graded on visual appeal and technical content

- Design Presentations - 20 minute formal presentation, 5 minutes questions

In addition to the formal requirements for reporting the students produce a poster highlighting the design as well as a group presentation that is evaluated by both industry representatives and academic staff other than the course instructors. Something that was tried in the term incorporating ID students was the notion of a mid-phase critique. This was scheduled in the middle of the conceptual design phase as an all day event during which design teams presented concepts in progress to their peers. Each team was required to prepare a poster or physical artifact that clearly communicated conceptual design ideas. Thirty minutes was available for each team to present design concepts and elicit critical feedback from colleagues. Students evaluated the effectiveness of conceptual design posters and presentations while the course instructors evaluated level of participation and quality of engagement demonstrated by the observing teams. The notion of a design critique was new to Mechanical Engineering students but is a common practice for ID students. While this was well received by the students they found it of limited worth in proportion to the time spent to prepare - this was especially true if the critique only confirmed that the students had explored a good range of possible solutions to the design. In the subsequent academic term the "critique" has become a mid phase design review in which the teams prepare a poster and the "critique" is held in the evening with refreshments and both academics and industry representatives circulating and chatting with the students about the concepts. This seems to be more palatable to all students who have full academic schedules and feel that they cannot spare more than a few hours.

During each project phase technical reports are read and evaluated by course instructors who provide written feedback on clarity of written communication, analytical and technical content as well as drawing effectiveness. From a student perspective report feedback has to be provided within a reasonable time period, usually one week, for it to have an impact on the design in progress and be perceived as useful. From an instructors standpoint this means that several times during the term there is a tremendous increase in work load as each must evaluate 20+ reports in a meaningful way and then meet to ensure that the comments and evaluation marks are consistent. Independent instructor evaluation coupled with a 5\% mark tolerance zone in which the team receives the higher of the two marks has been well received by senior design students.

\section{Challenges}

The largest challenges in the marriage of MecE and ID students arose due to the nature of the projects and individual student expectations. In most cases there was a good match between the project and student resources and skill sets. In these projects both disciplines benefited tremendously from the alliance and the project results reflected this happy result. Two situations created some problems: projects that did not have a large obvious industrial design component (examples shown in Table 1) and the expectation on the part of some of the MecE students that they could pass off technically complete designs to the ID students who would turn them into visual masterpieces. We must be very clear here that even if the project has a large industrial design component such as ergonomics it was not always the perception on the part of the engineering students that this was the case - they were looking for a visual component. The obvious solution to this "problem" in future is to spend more time educating the MecE students on the role that ID students can play in the projects beyond styling. Part of the misconception appears to stem from a pre-conceived notion based on the engineers' prior experiences or knowledge of the field of industrial design as a discipline solely dedicated to the styling of products. For example, the ID students are encouraged to develop an on-line portfolio to highlight their accomplishments in design. The portfolios are extremely visual and contain images of completed projects (hard goods such as furniture or advertizing media). These web pages were shared with the engineering students at the beginning of the project as proof of the designers past accomplishments and value in the project team. However, mechanical engineering students looking at this work sometimes jumped to the conclusion that the ID student contribution would be limited to the visual improvement of their designs and often failed to see the underlying effort went into the creation of the presented projects (material selection, ergonomics, manufacturing evaluation etc.). 
The second challenge that arose involved the division of labor. When the students form design teams they choose team members with appropriate skill sets (or friends that they hope will develop the appropriate skill sets in time). The skill sets are usually divided along the lines of analytical, numerical, CAD and technical writing. The addition of an ID student introduced the possibility of multiple additional skills but was in a good number of cases seen by the MecE students as only "visual communicators" rather than the full set of skills that the ID students really possess. This will be addressed in future offerings of the course by sitting down during the weekly design instructor/student group meetings and going through a skills inventory exercise. We will also evaluate the division of labor and assess the relative contributions of each group member.

The third challenge, and one that is difficult to do a priori, is to evaluate and quantify the relative ID components inherent in each design project. Where the device or process has a human interface (such as a machine that performs a task requiring human intervention) this is an easy determination for both the students and academic staff. Where the project involves the modification of an existing device, or a new device that apparently does not require human interaction, (i.e. down hole oil field tool or components inside a larger device) the ID component is more difficult to determine in advance. To address this paradox the possibility of engaging ID students as consultants to the Mechanical Engineering team is being explored. Mechanical engineering design teams will realize that they need the help of the ID students in order to ensure their designs are workable from an ergonomics, human factors, manufacturability as well as aesthetic perspective (even if it is only a parts replacement or repair). They also appreciate the ID students are very skilled at sketching and model building and if they are astute will engage the ID students very early in the design process, ideally at the specification development stage but certainly at the conceptual design stage. The engineering students will also be able to avail themselves of the services of the ID students for consulting on visual presentations of their ideas (reports, concepts, posters, presentations). There are some pitfalls in this mode of engaging ID students, and we would prefer that the ID students become full partners in the design but from an ID students perspective this approach might be more satisfying that simply joining an engineering team working on a project that does not hold capture the imagination or encourage meaningful engagement.

\section{Conclusions}

The goals for the design stream in Mechanical Engineering are principally to teach the students a rational design process and to reinforce planning and communication skills. Mec E 460 provides senior mechanical engineering students the opportunity to develop practical solutions to real design problems suggested by industry partners. Real world projects in the automotive, aeronautics, biomedical, energy, environmental, and industrial fields challenge student design teams to apply a broad range of knowledge gleaned from their undergraduate curriculum. New ideas, concepts and analytical methods are learned as a result of tackling these open ended design projects.

Methodical design processes are introduced and used as a framework around which innovative solutions are developed. Student teams are challenged to identify and independently explore sources of technical information, design expertise and manufacturing know-how. Commercial, technical and academic literature as well as direct contact with product vendors, engineers, technologists and fabricators provides students with the means to develop practical, engineered solutions to client projects.

When followed, the process invariably results in good, workable designs and when problems arise it can usually be traced back to deviations from the design process. The inclusion of the Industrial Design students has been overwhelmingly positive on both sides. While there are pitfalls to be avoided this is also true in the real world. By bringing the groups together and encouraging a sharing of ideas and skills the overall educational experience is enriched and each develops an appreciation for the others skills and knowledge. All engineering designs are for people and by definition when people interact with a device or process the success or failure depends on whether the device works or it really "works"! 
Table 1 - Des 502 / Mec E 460 Sample Design Projects - 2008 Fall Term

\begin{tabular}{|c|}
\hline $\begin{array}{l}\text { Air Transportable Spine Board } \\
\text { - Redesign an MRI compatible spinal traction board to allow easy and safe transport in medivac helicopter } \\
\text { and fixed wing aircraft for emergent treatment of a patient with spinal cord injury } \\
\text { - Perceived ID component - high } \\
\text { - Actual ID component - high } \\
\text { - Successful integration of all aspects of industrial design (ergonomics, human factors, manufacturing and } \\
\text { graphical communication) }\end{array}$ \\
\hline $\begin{array}{l}\text { Compact UAV Camera Gimbal } \\
\text { - Design a compact and lightweight pan-tilt camera gimbal system for use in small scale unmanned aerial } \\
\text { vehicles (UAV) } \\
\text { - Perceived ID component - low } \\
\text { - Actual ID component - moderate } \\
\text { - Team struggled to identify and successfully incorporate industrial design principles into this project }\end{array}$ \\
\hline $\begin{array}{l}\text { Cylinder Head Workstation } \\
\text { - Develop an ergonomic remanufacturing workstation for natural gas engine head repair and overhaul } \\
\text { - Perceived ID component - moderate } \\
\text { - Actual ID component - moderate } \\
\text { - Human factors, ergonomic design and visual appeal were important elements of this design project }\end{array}$ \\
\hline $\begin{array}{l}\text { All Terrain Manual Wheelchair } \\
\text { - Use an existing industrial variable geometry track module concept to design an adaptation for wheel chair } \\
\text { use which enhances indoor functionality over uneven surfaces and significantly enhances outdoor access to } \\
\text { unprepared areas } \\
\text { - Perceived ID component - high } \\
\text { - Actual ID component - high } \\
\text { - Design team successfully identified and incorporated appropriate industrial design practices into this project. } \\
\text { Extremely high team cohesion and ID leadership contributed to project success. Excellent work done on } \\
\text { communicating design intent. }\end{array}$ \\
\hline $\begin{array}{l}\text { FSAE Composite Drive Shaft } \\
\text { - Design a lightweight composite drive shaft for the } 2009 \text { Formula SAE vehicle } \\
\text { - Perceived ID component - low } \\
\text { - Actual ID component - low } \\
\text { - Team struggled to identify and successfully incorporate industrial design principles into this project. } \\
\text { Excellent work done on communicating design intent. }\end{array}$ \\
\hline $\begin{array}{l}\text { Incendiary Projectile Gun } \\
\text { - Design a lightweight antiroll system for the front A-arm suspension } \\
\text { - Perceived ID component - low } \\
\text { - Actual ID component - moderate } \\
\text { - Design team successfully identified and incorporated appropriate industrial design practices into this project. } \\
\text { Extremely high team cohesion contributed to project success. Excellent work done on communicating } \\
\text { design intent. }\end{array}$ \\
\hline $\begin{array}{l}\text { Catalytic Heater Internal Tube Ignition } \\
\text { - Design an internal tube heater used to initiate catalytic combustion heaters } \\
\text { - Perceived ID component - low } \\
\text { - Actual ID component - low } \\
\text { - Design team struggled to incorporate industrial design practices into this project. }\end{array}$ \\
\hline $\begin{array}{l}\text { Rehab Robot Mechanical Interface } \\
\text { - Design an efficient and patient friendly mechanical interface to couple a cable robot and human patient } \\
\text { - Perceived ID component - high } \\
\text { - Actual ID component - high } \\
\text { - Design team successfully identified and incorporated appropriate industrial design practices into this project. } \\
\text { Extremely high team cohesion and ID leadership contributed to project success. }\end{array}$ \\
\hline
\end{tabular}

